OPEN ACCESS

Edited by:

Marco Salerno,

Italian Institute of Technology (IIT), Italy

Reviewed by:

Tadeja Kosec,

Slovenian National Building and Civil

Engineering Institute, Slovenia

Milos B. Djukic,

University of Belgrade, Serbia

*Correspondence:

Luca Tortora

luca.tortora@uniroma3.it

Specialty section:

This article was submitted to

Environmental Materials,

a section of the journal

Frontiers in Materials

Received: 15 November 2019

Accepted: 30 January 2020

Published: 18 February 2020

Citation:

Graziani V, lorio $M$, Albini $M$ Riccucci C, Di Carlo G, Branchini P and Tortora $L$ (2020) Metals and Environment: Chemical Outputs From the Interaction Between Gilded

Copper-Based Objects and Burial

Soil. Front. Mater. 7:32

doi: 10.3389/fmats.2020.00032

\section{Metals and Environment: Chemical Outputs From the Interaction Between Gilded Copper-Based Objects and Burial Soil}

\author{
Valerio Graziani ${ }^{1}$, Morena lorio ${ }^{1}$, Monica Albini ${ }^{2}$, Cristina Riccucci ${ }^{2}$, Gabriella Di Carlo ${ }^{2}$, \\ Paolo Branchini ${ }^{1}$ and Luca Tortora ${ }^{1,3 *}$
}

${ }^{1}$ Surface Analysis Laboratory, INFN Roma Tre, Rome, Italy, ${ }^{2}$ Institute of Nanostructured Materials, National Research Council, Research Area Montelibretti, Rome, Italy, ${ }^{3}$ Department of Sciences, Roma Tre University, Rome, Italy

Three-dimensional chemical mapping was adopted to investigate an ancient fire-gilded buckle found in Rome. Time-of-flight secondary ion mass spectrometry (ToF-SIMS) and scanning electron microscopy with energy dispersive spectroscopy (SEM-EDS) were used to detect and locate degradation products aiming to identify the alteration processes. Inorganic and organic compounds present in the outermost part of such a class of cultural heritage objects can be considered the result of long-term interaction with the burial environment. ToF-SIMS depth profiling experiments can provide chemical information at the molecular level and high resolved spatial information (about $1 \mu \mathrm{m}$ laterally, and $1 \mathrm{~nm}$ in depth). In this work, the attention was focused on the identification and localization of the ionic and molecular species involved in the degradation process. Results showed the presence of copper oxides, chlorides, and sulfides as common corrosion products but also the presence of species related to copper and bronze corrosion process, such as atacamite and its polymorphs. 3D maps for all the relevant molecular species allowed to visualize at the same time the eruption of copper chlorides throughout the micro/nanochannels present on the gold surface, the recrystallization of compounds of minor elements from the substrate, a pathway followed by silico-aluminates from the surface toward the internal corrosion layers, but mostly the evidence of biological activity of Sulfur Reducing Bacteria (SRB) living in anaerobic conditions.

Keywords: gilding, corrosion, copper, bronze disease, gold, soil, ToF-SIMS

\section{INTRODUCTION}

Mercury-gilding is one of the most complex techniques used in the past millennia to apply a thin layer of gold or silver onto the surface of a metal substrate. It was used by arts men and craftsmen for the decoration of jewels, statues, artworks, weapons, armors, ornaments, coins, and other everyday objects; sometimes in a fraudulent manner (Ingo et al., 2013). Two different methods for mercury gilding were available in the past (Lins and Oddy, 1975; Oddy, 1981, 1990; Anheuser, 1996, 1997, 2000).

The first one approaches the use of mercury as a "glue" able to attach a gold leaf to the substrate by forming an amalgam at the interface (namely, cold mercury gilding). 
The second method is based on a solid-state reaction involving the use of an Au-Hg amalgam with doughy consistency, which can be applied to create a preliminary coarse coating of the object. This paste is produced by simple grinding gold dust with mercury and it requires a clean and oxide-free metal substrate. After that, a thermal treatment for a few minutes (heating in air at about $250-350^{\circ} \mathrm{C}$, below the mercury boiling point at $357^{\circ} \mathrm{C}$ ) is needed to volatilize the large part of the mercury and leave a gold film, whose thickness ranges from a few tenths of micron to about one micron (Ingo et al., 2013). A variable amount of residual mercury can be found in the gold layer due to an incomplete release (Anheuser, 1996, 1997, 2000). Finally, a mechanical finishing using bone or agate burnishers was always required to create a smooth, shiny, gold-like surface (Lins and Oddy, 1975; Oddy, 1981, 1990; Ingo et al., 2013).

However, the second manufacturing process intrinsically contains even the causes of the typical corrosion mechanisms. The aforementioned process produces a well-bonded but irregular and porous layer of gold. Furthermore, a thermal treatment at too high temperature or a too fast approach to the mercury boiling point can increase the extent of the irregularity due to the formation of gas bubbles. Defects in the multilayer architecture are represented by micro/nanochannels induced by the mercury evaporation, micro-discontinuities or breakages of the golden layer leaving uncovered the non-noble metal substrate. For these reasons, a mechanical finishing is mandatory to obtain a regular, smooth, and gold-like surface.

The typology of degradation phenomena and corrosion products depends on the surrounding environment in which they lived, in some cases for about two millennia (Scott, 1990, 1991; Robbiola et al., 1988; Ingo et al., 2002, 2019; Abdelhamid et al., 2010). The samples here studied underwent underwater burial for a long time of about four centuries thus representing a chance to study degradation phenomena of this type of artifact occurring in this specific condition. Understanding the chemical processes involved in the deterioration of gilded objects in a such extreme environment as well as the chemical and structural modifications due to a long-term interaction with organic/biological materials could pave the way for new strategies for the conservation-restoration of these pieces of cultural heritage.

The sample studied in this work is part of a couple of firegilded metallic buckles found during the dredging of Tiber river (Rome, Italy) and dated back to 16 th -17 th century AD. They were the subject of previous works of the authors aiming to give elemental information about the structure of the artifacts, the corrosion products, and the degradation phenomena that occurred during the burial (Ingo et al., 2016, 2018). In the present work, we focused the attention on giving a more detailed information about the chemical species involved in such phenomena. In particular, organic and inorganic compounds were detected providing, at the same time, three-dimensional chemical maps of the degradation products. Such chemical and structural information were acquired by using ToF-SIMS technique in dual beam mode. The 3D distribution of the molecular ion species was used to correlate degradation products with changes in the sample multilayer structure. In the last decade, only a few works considered corrosion mechanisms and products in ancient gilded artifacts similar to those here reported (Ingo et al., 2013; Chiavari et al., 2015; Masi et al., 2016), among which an even shorter number of studies employed SIMS technique (Lechtman, 1984; De Ryck et al., 2003) providing also results about depth profiling (Yin et al., 2008; Ingo et al., 2018). On the other hand, the majority of the literature regards corrosion in non-gilded artifacts, studies in manufacturing techniques or studies on gilding of different, non-metallic artworks (Schreiner and Grasserbauer, 1985; Hackea et al., 2004; Adriaens, 2005; Dowsett et al., 2005; Van Ham et al., 2005; Bonaduce et al., 2007; Balta et al., 2009; Sandu et al., 2011; Tortora et al., 2014; Biocca et al., 2016; Di Tullio et al., 2016; Iorio et al., 2019). To the best of our knowledge, this is the first work that correlates structural information and three-dimensional distribution of organic and inorganic chemical species coming from corrosion process of an ancient gilded artifact.

\section{MATERIALS AND METHODS}

\section{Samples}

The sample surface was cleaned up by using first distilled water and then ethanol to remove adventitious carbon contamination and to assure dehydration (Ingo et al., 2016, 2018). The buckle was subsampled by taking a small representative fragment both of the layered corrosion products (patina) and the underlying metal substrate. To preserve the structure of the patina, the subsampled fragments were embedded in a suitable resin for $24 \mathrm{~h}$ and carefully micro-sectioned by using a diamond saw. The section was polished with different $\mathrm{SiC}$ papers gradually increasing until 1,200 grit. The last polishing procedure was performed by using diamond pastes up to $0.25 \mu \mathrm{m}$.

Part of the analyses was carried out on the surface of the entire objects while the remaining techniques employed the embedded subsample.

\section{Time of Flight-Secondary Ion Mass Spectrometry (ToF-SIMS)}

ToF-SIMS technique was used to study chemical features and their distribution on the sample surface and in depth (3D chemical mapping). Measurements were performed by using a ToF-SIMS 5-300 (ION-TOF Munster, Gmbh, Germany) secondary ion mass spectrometer, equipped with bismuth liquid metal ion gun (LMIG) and cesium ion sputter gun. The sample was first analyzed in bunched mode using $\mathrm{Bi}^{+}$at $30 \mathrm{keV}$ as a primary beam with dose density below the static limit $\left(<10^{12}\right.$ ions $/ \mathrm{cm}^{2}$ ) to distinguish deteriorated areas from the unaltered. A low energy electron flood gun $(20 \mathrm{eV})$ was utilized to investigate the non-conductive blackish degraded areas. ToF-SIMS depth profiles were acquired in dual beam mode, using $\mathrm{Bi}^{+}$at $30 \mathrm{keV}$ and $15.6 \mathrm{~ns}$ pulse width as primary ions and $\mathrm{Cs}^{+}$gun at $2 \mathrm{keV}$ as erosion beam, operating in interlaced mode. Cesium ion dose density was estimated as $\sim 10^{18} \mathrm{ion} / \mathrm{cm}^{2}$. The analysis area (100 $\left.\times 100 \mu \mathrm{m}^{2}\right)$ was set at the center of the sputter region $(300 \times 300$ $\left.\mu \mathrm{m}^{2}\right)$. Special attention was paid to choose the analysis area on a flat portion of the sample surface. All the images were collected 




FIGURE 1 | (A) Stereomicroscope image of the buckle with four sampling areas; (B) FE-SEM BSE image of the cross-section of a subsample of the buckle; (C) FE-SEM SE image of the gold grains constituting the gilded layer (top view); (D) EDS analysis on a representative white island in the matrix; (E) EDS analysis on a gold grain; (F) EDS analysis on a corroded area.

at a pixel density of $128 \times 128$ pixels, with a lateral resolution of $2 \mu \mathrm{m}$ approximately. Secondary ions were extracted at $2 \mathrm{keV}$ voltage and traveled through the ToF analyzer for a time of 100 $\mu \mathrm{s}$ per cycle allowing to obtain an $\mathrm{m} / \mathrm{z}$ range from 1 to 800 . Mass spectra were acquired in both positive and negative ion mode. All the ToF-SIMS images shown were normalized to the total ion image and processed with an averaging filter to remove topographical effects, and salt-and-pepper noise. All the data presented in this case study are shown in negative polarity, even for elements that are usually easier to detect in positive polarity. A stylus profilometer P7 (KLA-Tencor, San Jose, CA) was used to measure the depth of the ToF-SIMS craters.

\section{Scanning Electron Microscopy With Energy Dispersive Spectroscopy (SEM-EDS)}

$\mathrm{LaB}_{6}$ filament equipped SEM (Stereoscan 360, Cambridge, UK) and highly brilliant Field Emission SEM (LEO Gemini 1530, Zeiss, Germany) with high spatial resolution were employed to study morphological and chemical features, coupled with INCA 250 and INCA 450 energy-dispersive X-ray spectrometers (EDS, by Oxford Instruments Analytical, UK), respectively. Secondary electron (SE) and backscattered electron (BSE) images were collected with acceleration voltages up to $20 \mathrm{kV}$, both on the surface and the cross-section of the samples. Before the analysis, the surface of the sample was coated with a thin layer of carbon or chromium to avoid charging effects. The former was deposited by using an Emitech sputter coater K550 unit, a K250 carbon coating attachment and a carbon cord at a pressure of $1 \times 10^{-2}$ mbar to obtain an $\sim 3.0 \mathrm{~nm}$ thick film. The latter was deposited by using a Bal-Tech SCD 500 equipped with turbo pumping for ultra-clean preparations at a pressure of $5 \times 10^{-3}$ mbar in order to obtain an $\sim 0.5 \mathrm{~nm}$ thick film.

\section{RESULTS AND DISCUSSION}

Figure 1A shows the buckle studied in this work. The gold layer still covers a large part of the sample surface even if several damaged areas are present in correspondence to the borders and decorative reliefs. The presence of greenish corrosion compounds originating from the copper substrate can be easily appreciated with the optical microscope. In the same figure, the four analyzed areas are highlighted as well. It is evident that the surface of the sample is poorly planar and homogeneous. FESEM BSE cross-section image (Figure 1B) gives representative details of the internal structure of the object. The EDS analysis in Figure 1E confirms the presence of mercury and thus the manufacturing processes afore introduced. In this cross-section, the gold layer is continuous and tight to the substrate. It is about $2-3 \mu \mathrm{m}$ thin with irregular thickness. Gold grains are well distinguishable with visible traces due to the finishing process. Some of the grains are quite isolated, with a few points in contact with the adjacent ones. Under the gold layer, the grains of the altered substrate are distinguishable, thus evidencing the crystalline nature of this layer. The presence of spaces and interstices homogeneously dispersed along the whole thickness indicates that this layer could be the product of a reaction or recrystallization starting from an even inner copper substrate (image not shown). The EDS analysis in Figure 1F shows the presence of sulfur and chlorine in addition to that expected of copper, confirming the penetration of active corrosive agents from the external environment which could play a role in such reaction-recrystallization process. White islands in the substrate copper-based matrix (not shown) are composed of lead (Ingo et al., 2018), analogously to those present also in the altered layer (Figure 1D). This was usually added to reduce the melting temperature of copper or bronze, resulting in easier-to-cast 

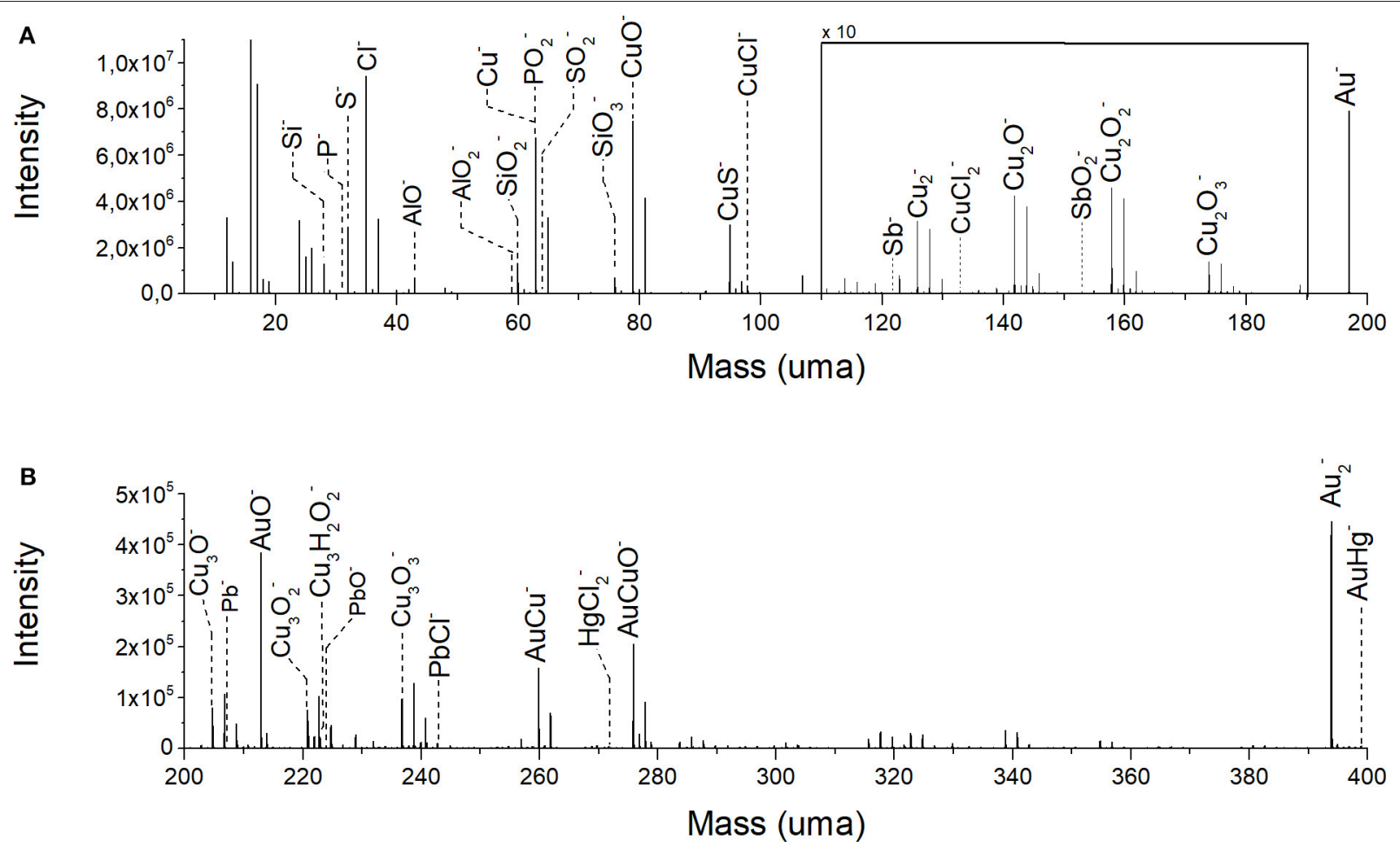

FIGURE 2 | ToF-SIMS negative ion spectrum of the analyzed volume: (A) mass fragmentation range from $\mathrm{m} / \mathrm{z} 5$ to 150; (B) mass fragmentation range from $\mathrm{m} / \mathrm{z} 150$ to 400 .

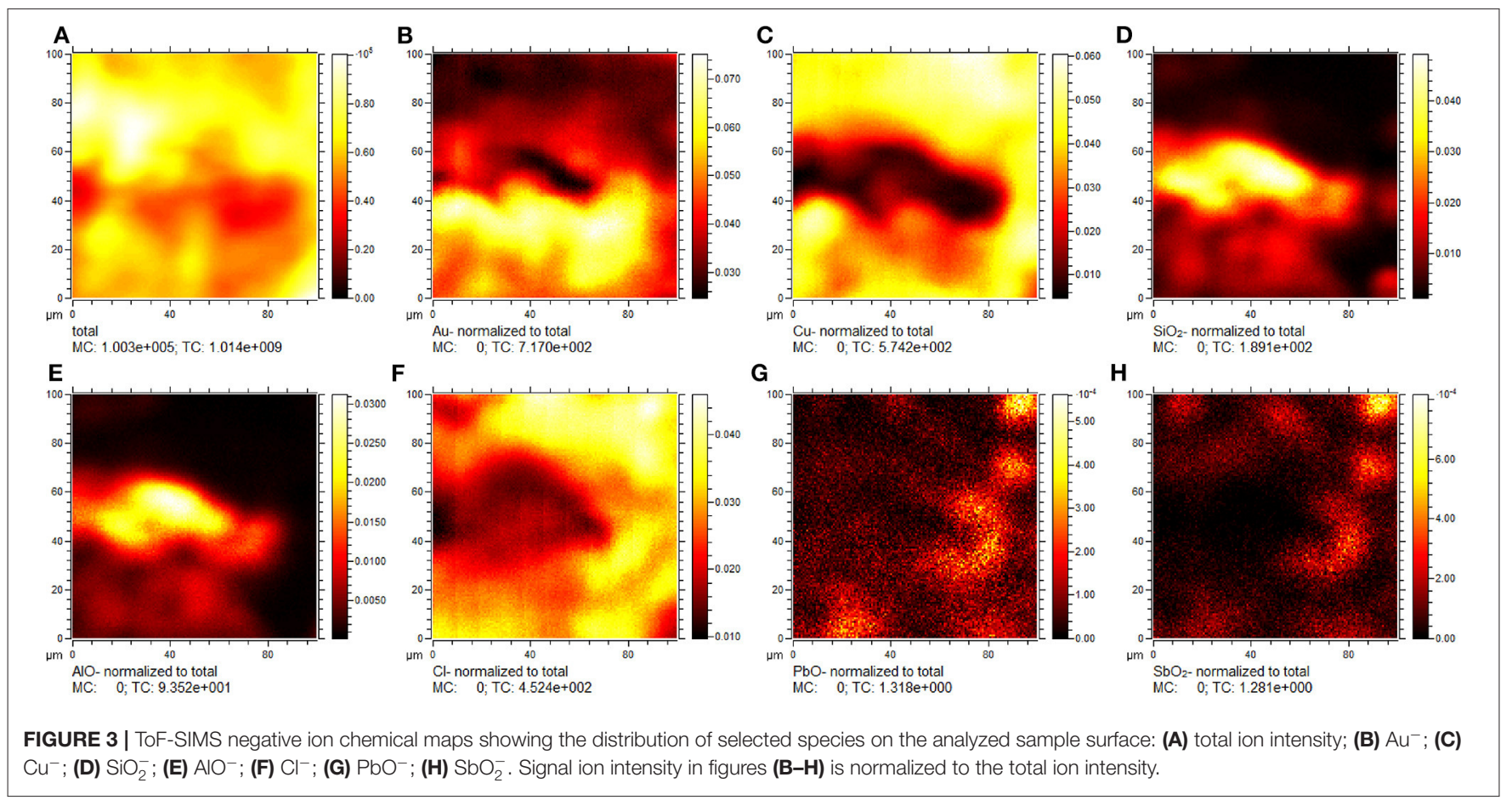

alloys. In this case, this could have been used in the fabrication of the copper substrate. The surface of the object at higher magnifications shows the aggregation of gold grains and the interstices among them (Figure 1C). Grain dimensions are quite homogeneous and range around $2 \mu \mathrm{m}$. Interstices have lower diameters. The very small pores on the grains $(\sim 20 \mathrm{~nm})$ are 
the channels created during the evaporation of the mercury. In the lower-left corner of the image, some of the traces left by the ancient polishing procedures are clearly visible (about $1 \mu \mathrm{m}$ wide). Figures 1B,C confirm the high irregularity of the sample surface, as stated before.

A representative ToF-SIMS mass spectrum in negative ion mode of the gilded object is reported in Figure 2. The mass spectrum was obtained collecting all the ion signals during the depth profiling experiment. As expected, the most intense ion signals are $\mathrm{Au}^{-}\left(\mathrm{m} / \mathrm{z}\right.$ 196.96), $\mathrm{Cu}^{-}$(m/z 63.54), $\mathrm{Cu}_{2}^{-}$ $\left(\mathrm{m} / \mathrm{z}\right.$ 127.08), and $\mathrm{AuCu}^{-}(\mathrm{m} / \mathrm{z}$ 259.89) and their related oxygen-containing species $\mathrm{CuO}^{-}(\mathrm{m} / \mathrm{z} 78.93), \mathrm{Cu}_{2} \mathrm{O}^{-}(\mathrm{m} / \mathrm{z}$ 141.85), $\mathrm{Cu}_{2} \mathrm{O}_{2}^{-}$(m/z 157.85), $\mathrm{Cu}_{2} \mathrm{O}_{3}^{-}(\mathrm{m} / \mathrm{z} 173.85), \mathrm{Cu}_{3} \mathrm{O}^{-}$ (m/z 204.79), $\mathrm{Cu}_{3} \mathrm{O}_{2}^{-}$(m/z 220.79), $\mathrm{Cu}_{3} \mathrm{O}_{3}^{-}$(m/z 236.78), and $\mathrm{AuCuO}^{-}(\mathrm{m} / \mathrm{z}$ 275.89). Secondary ions with a lower signal intensity are $\mathrm{CuCl}^{-}\left(\mathrm{m} / \mathrm{z}\right.$ 97.90), $\mathrm{Sb}^{-}\left(\mathrm{m} / \mathrm{z}\right.$ 121.76), $\mathrm{CuCl}_{2}^{-}(\mathrm{m} / \mathrm{z}$ 132.86), $\mathrm{SbO}_{2}^{-}$(m/z 152.89), $\mathrm{Cu}_{3} \mathrm{H}_{2} \mathrm{O}_{2}^{-}$(m/z 224.79), $\mathrm{HgCl}_{2}^{-}$ $\left(\mathrm{m} / \mathrm{z}\right.$ 270.92), and $\mathrm{AuHg}^{-}(\mathrm{m} / \mathrm{z}$ 398.93). As reported in the previous works (Ingo et al., 2016, 2018), the copper oxide ions are originated from the outermost layer of the substrate underlying the gold layer. In this case, it is worth to note the presence of the signal of $\mathrm{Cu}_{3} \mathrm{H}_{2} \mathrm{O}_{2}^{-}$ion. The copresence of $\mathrm{Cu}_{3} \mathrm{H}_{2} \mathrm{O}_{2}^{-}$and $\mathrm{CuCl}_{2}^{-}$ ions suggests the formation of atacamite $\left[\mathrm{CuCl}_{2} \cdot 3 \mathrm{Cu}(\mathrm{OH})_{2}\right]$ as a degradation product of the copper substrate. Details about the manufacturing process were revealed by the presence of mercury (in the adduct $\mathrm{AuHg}^{-}$) and lead. In fact, the amount of mercury can be explained as a residual of the use of $\mathrm{Hg}-\mathrm{Au}$ amalgam for the realization of the gold plate. For what concerns the presence of lead $\left[\mathrm{Pb}^{-}\left(\mathrm{m} / \mathrm{z}\right.\right.$ 207.20), $\mathrm{PbO}^{-}$(m/z 223.97), and $\left.\mathrm{PbCl}^{-}(\mathrm{m} / \mathrm{z} 242.94)\right]$, it could be migrated from the copper substrate toward the gold surface due to alteration processes during the long-term burial. Lead and mercury can give rise to additional compounds constituting part of the corrosion patina, as suggested by the following detected ions: $\mathrm{PbO}^{-}, \mathrm{PbCl}^{-}$, and $\mathrm{HgCl}_{2}^{-}$. Antimony can be imputed to a lead impurity in the $\mathrm{Cu}-$ $\mathrm{Pb}$ alloy. In the low-mass range (Figure 2A), further ion signals are originated from $\mathrm{S}^{-}(\mathrm{m} / \mathrm{z} 32.06), \mathrm{CuS}^{-}(\mathrm{m} / \mathrm{z} 94.90), \mathrm{Cl}^{-}(\mathrm{m} / \mathrm{z}$ 34.96), $\mathrm{Si}^{-}$(m/z 27.97), $\mathrm{AlO}^{-}$(m/z 42.97), $\mathrm{AlO}_{2}^{-}$(m/z 58.97), $\mathrm{SiO}_{2}^{-}$(m/z 59.96), $\mathrm{SiO}_{3}^{-}$(m/z 75.96), $\mathrm{P}^{-}$(m/z 30.97), $\mathrm{PO}_{2}^{-}$(m/z 62.96), and $\mathrm{SO}_{2}^{-}(\mathrm{m} / \mathrm{z}$ 63.96). In general, the noble metal layer of ancient metallic artifacts, subjected to corrosion phenomena, has often an irregular surface characterized by fractures, cracks, and nano-channels induced by the fabrication procedure (Ingo et al., 2018). These surface defects represent preferential access points for aggressive soil species, organic contaminants and biological material dissolved in water that come in contact with the less noble underlying copper substrate. The intense signal from $\mathrm{S}^{-}, \mathrm{SO}_{2}^{-}, \mathrm{P}^{-}$, and $\mathrm{PO}_{2}^{-}$ions could be mainly due to environmental contamination. In particular, the significant presence of such sulfur- and phosphorus- based compounds can be related to the biological activity of Sulfur Reducing Bacteria (SRB) living in anaerobic conditions, namely those present in the burial condition at the ground of the Tiber river (Pope et al., 1968; Podany and Considine, 1994; Bastidas et al., 2008). The interaction between environmental aggressive chemical species and the metal composite object produces galvanic areas with consequent complex corrosion phenomena. Examples of these phenomena are the surfacing of degradation products having a molar volume increased compared to the starting material (Abdelhamid et al., 2010; Bastidas et al., 2010; Ingo et al., 2013) or the formation of crystalline nodules and multilayered patinas (Scott, 1985). Moreover, elements present inside the metallic matrix can move toward the surface and rearrange in new spatial configurations, originating also new compounds and structures. Finally, external compounds and minerals can deposit on the object defected surface from the surrounding environment and penetrate its structure. In this case, this is suggested by the presence of the $\mathrm{AlO}^{-}$and $\mathrm{SiO}_{2}^{-}$ion signals which could be interpreted as contamination from clay.

2D chemical maps of some constituents from a representative area of the sample are reported in Figure 3. As mentioned above, the surface of the sample is highly inhomogeneous with spaces and interstices due to the presence of aggregates of gold grains. In this case, the $\mathrm{Au}^{-}$and $\mathrm{Cu}^{-}$distribution (Figures 3A,B) highlights the presence of a channel with a length of $80 \mu \mathrm{m}$ and a width of $20 \mu \mathrm{m}$, approximately. This channel seems to be occupied by Si- and Al-based compounds (Figures 3C,D) supporting the hypothesis of contamination from clay. The degradation of the copper substrate is confirmed by the colocalization of the $\mathrm{Cl}^{-}$ion signal with the $\mathrm{Cu}^{-}$ion (Figure 3E). Furthermore, the presence of $\mathrm{Pb}^{-}$and $\mathrm{Sb}^{-}$ion signals can be indicative of a specific production process.

In depth profiling experiments, changes in signal intensity of elements and compounds can be measured in function of depth, as shown in Figure 4. In secondary ion mass spectrometry, different physico-chemical and geometrical factors contribute to the signal intensity of each ion peak. In this case, it is not possible to exactly correlate sputter time and sputter depth considering that the observed secondary ion signal intensity can be affected by several aspects, such as the complex architecture of the sample, the extremely irregular sample surface, and the inhomogeneous chemical distribution of elements and compounds. Therefore, in the depth profiles reported below the ion signal intensity was represented as a function of the sputter time. However, the depth of the ToF-SIMS craters was measured in order to estimate the volume of material removed in the sputtering process. Depth profiles were reported in two separate graphs in order to better observe changes in signal intensity Figures 4A,B. As expected, the signal intensity of the $\mathrm{Au}^{-}$in Figure 4A shows an initial fast growth. After that, the ion signal slightly decreases without reaching zero counts. The $\mathrm{AuHg}^{-}$profile confirms the accumulation of mercury in the outermost part of the gold layer. The depth profiles of $\mathrm{Cu}^{-}$as well as those of the related oxygen, chlorine, and sulfur adducts $\left(\mathrm{CuO}^{-}, \mathrm{Cu}_{2} \mathrm{O}^{-}, \mathrm{CuCl}^{-}, \mathrm{CuS}^{-}\right)$ show a common behavior with a fast growth at the beginning and in the interval $750 \div 1,470 \mathrm{~s}$, then a slow increase till the end of the analysis. The very similar trend of depth profiles of $\mathrm{Cu}^{-}$ and $\mathrm{CuCl}^{-}$makes evident the close relationship between these species. On the other hand, the profile for $\mathrm{CuCl}_{2}^{-}$strongly differs from the previous ones, showing a decreasing trend till $\sim 750 \mathrm{~s}$ and a slow-growing trend after $\sim 3,000$ s. The $\mathrm{Cu}_{3} \mathrm{H}_{2} \mathrm{O}_{2}^{-}$signal is more intense near the surface and then slowly decreases with the depth of the sample. In Figure 4B, the $\mathrm{Cl}^{-}$profile shows a fast growth at the beginning till $\sim 150 \mathrm{~s}$; then it slightly decreases till 

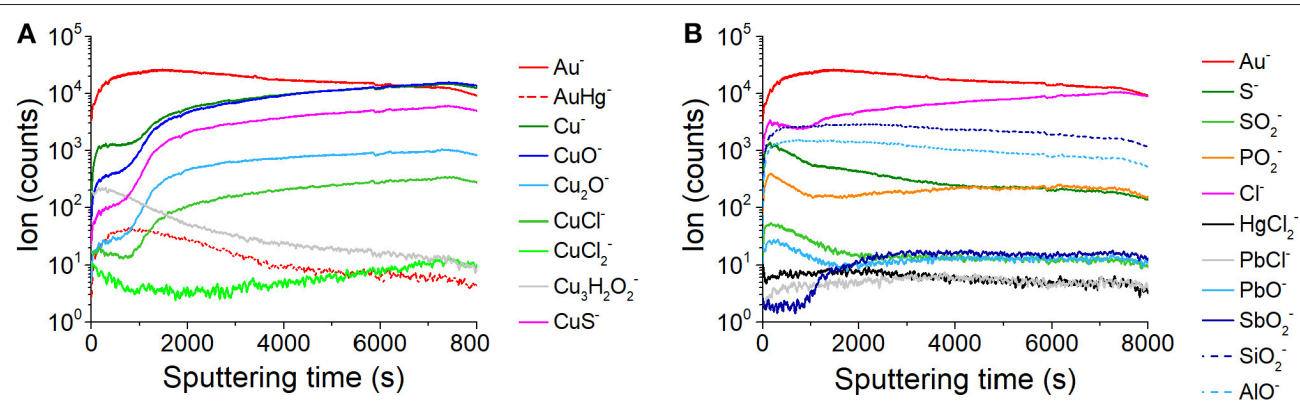

FIGURE 4 | Depth profiles for selected ions revealed during the analysis: (A) ion signals characteristic of the artifact and corrosion patina constituents; (B) ion signals related to other corrosion products and materials from the external environment.

TABLE 1 | Correspondence among observed secondary ions, structural information, and source attribution in the object/environment system.

\begin{tabular}{|c|c|c|}
\hline $\begin{array}{l}\text { Observed } \\
\text { secondary ions }\end{array}$ & $\begin{array}{l}\text { Structural } \\
\text { information }\end{array}$ & Source attribution \\
\hline $\mathrm{Au}^{-}, \mathrm{AuHg}^{-}$ & Metallic Au & Gold Layer \\
\hline $\mathrm{PbO}^{-}$ & $\mathrm{Pb}$ oxides & $\begin{array}{l}\text { Alloying element with copper } \\
\text { (white islands in the substrate } \\
\text { copper-based matrix) }\end{array}$ \\
\hline $\mathrm{SbO}_{2}^{-}$ & Sb oxides & Lead impurity in the Cu-Pb alloy \\
\hline $\mathrm{Cu}^{-}, \mathrm{CuO}^{-}, \mathrm{Cu}_{2} \mathrm{O}^{-}$ & $\mathrm{Cu}_{2} \mathrm{O}$ (cuprite) & Corrosion patina (red corrosion) \\
\hline $\mathrm{Cu}^{-}, \mathrm{CuCl}^{-}$ & CuCl (nantokite) & Corrosion patina (green Corrosion) \\
\hline $\begin{array}{l}\mathrm{Cu}^{-}, \mathrm{CuCl}^{-}, \mathrm{CuCl}_{2}^{-} \\
\mathrm{Cu}_{3} \mathrm{H}_{2} \mathrm{O}_{2}^{-}\end{array}$ & $\begin{array}{l}\mathrm{CuCl}_{2} \cdot 3 \mathrm{Cu}(\mathrm{OH})_{2} \\
\text { (atacamite) }\end{array}$ & Corrosion patina (green Corrosion) \\
\hline $\mathrm{Cl}^{-}, \mathrm{S}^{-}, \mathrm{SO}_{2}^{-}, \mathrm{PO}_{2}^{-}$ & $\begin{array}{l}\mathrm{Cl}, \mathrm{H}_{2} \mathrm{~S}, \mathrm{SO}_{4}{ }^{2-} \\
\mathrm{PO}_{4}{ }^{3-}\end{array}$ & $\begin{array}{l}\text { Environmental contamination and/or } \\
\text { Biological Activity of Sulfur Reducing } \\
\text { Bacteria(SRB) }\end{array}$ \\
\hline $\mathrm{CuS}^{-}$ & Cus & Corrosion patina \\
\hline $\mathrm{HgCl}_{2}^{-}, \mathrm{PbCl}^{-}$ & $\mathrm{HgCl}_{2}, \mathrm{PbCl}_{2}$ & Corrosion patina \\
\hline $\mathrm{SiO}_{2}^{-}$and $\mathrm{AlO}^{-}$ & Aluminosilicates & Contamination from soil (clay) \\
\hline
\end{tabular}

$\sim 950$ s and finally shows a new growing trend till the end of the acquisition. The $\mathrm{HgCl}_{2}^{-}$and $\mathrm{PbCl}^{-}$profiles are about constant during the entire acquisition. Profiles for $\mathrm{S}^{-}, \mathrm{SO}_{2}^{-}, \mathrm{PO}_{2}^{-}, \mathrm{PbO}^{-}$ ions show a very similar trend, with a rapid increase in the first $\sim 150 \mathrm{~s}$ and a final decreasing trend. The profile of $\mathrm{SbO}_{2}^{-}$ shows a growth after $\sim 860 \mathrm{~s}$, then a constant trend till the end of the acquisition. The profiles of $\mathrm{SiO}_{2}^{-}$and $\mathrm{AlO}^{-}$are strongly coherent throughout the duration of the analysis, showing the same maximum curvature point at $\sim 170 \mathrm{~s}$, a common maximum at $\sim 450 \mathrm{~s}$ and a common trend of decrease. To summarize and correlate the most relevant ions revealed by ToF-SIMS with the structural information, and source attribution in the object/environment system, the Table $\mathbf{1}$ is given.

The 3D spatial distribution of signal intensity can be useful to recognize structures in a complex material and it is shown for some relevant chemical species in Figure 5. Comparing the distribution of $\mathrm{Au}^{-}$and $\mathrm{AuHg}^{-}$, an empty space can be appreciated in the middle of the analyzed volume; this constitutes a sort of channel connecting the burial environment with the substrate. Considering that the sputtered away volume represented in the $3 \mathrm{D}$ renders was estimated to be $100 \times$ $100 \times 8 \mu^{3}$ by using profilometry, the gold signals are widely distributed, but mostly in the first 3-4 microns of the sample. The $\mathrm{Au}^{-}$ion distribution puts in evidence the sample surface morphology and in particular the channel in the middle. Furthermore, observing the $3 \mathrm{D}$ map of the adduct $\mathrm{AuHg}^{-}$, it is interesting to note that the ion signal distribution reveals that the mercury is more concentrated on the surface of the sample as well as the surface of the channel. Copper, copper oxides $\left(\mathrm{CuO}^{-}, \mathrm{Cu}_{2} \mathrm{O}^{-}\right), \mathrm{Cl}^{-}$, copper chlorides $\left(\mathrm{CuCl}^{-}, \mathrm{CuCl}_{2}^{-}\right)$ions are prevalently located under the gold layer. Chloride ions could migrate and spread throughout the mass of copper, being both the micro- and nanochannels induced by amalgam evaporation and the central channel preferential ways of penetration of the corrosion agents. The presence of copper chlorides (in particular nantokite, $\mathrm{CuCl}$ ) is well in accordance with the evidence of newly formed compounds having erupted throughout the gold surface causing its spalling, break up, and partial detachment caused by the difference of molar relative volume between these minerals and copper. Furthermore, cuprite plays also a crucial role in the corrosion phenomena of copper-based alloys as discussed by Lucey (1972) and has been considered to act as an electrolytic membrane allowing the transport of anions, such as $\mathrm{Cl}^{-}$or Ocontaining radicals inward, and cuprous ions outward. This is in accordance with the experimental evidence obtained by ToFSIMS, as well: (1) the distribution of the signals from $\mathrm{Cl}^{-}$is not only ubiquitous and clearly overlapping to that of $\mathrm{Cu}^{-}$in the entire analyzed volume but also is continuously growing; (2) depth profiles of $\mathrm{CuO}^{-}, \mathrm{Cl}^{-}$and $\mathrm{CuCl}^{-}$share very similar growth rates while $\mathrm{Cu}_{2} \mathrm{O}^{-}$shows a slightly lower rate. $\mathrm{Cu}_{3} \mathrm{H}_{2} \mathrm{O}_{2}^{-}$ $3 \mathrm{D}$ map shows that this chemical specie is concentrated on the top surface with some signals originating from the central part of the volume, filling the channel defined by the other species. The coexistence of signals of $\mathrm{Cu}_{3} \mathrm{H}_{2} \mathrm{O}_{2}^{-}$and $\mathrm{CuCl}^{-}$could prove the specific presence of atacamite (or its polymorphs) among all the possible chlorides. This points out also that the central channel is not only an available passage for external corrosion agents but allows accumulating both alteration products emerging from the inside of the object and materials from the external environment. $3 \mathrm{D}$ renders for $\mathrm{S}^{-}, \mathrm{SO}_{2}^{-}$, and $\mathrm{CuS}^{-}$ions show that sulfurcontaining compounds are present in the entire analyzed volume, being sulfides formed (or preserved) mainly under the surface 


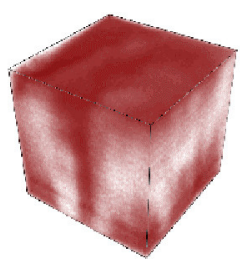

Au-

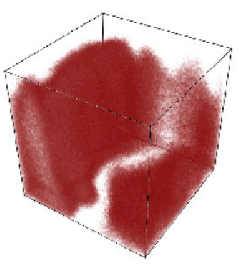

$\mathrm{Cu}_{2} \mathrm{O}-$

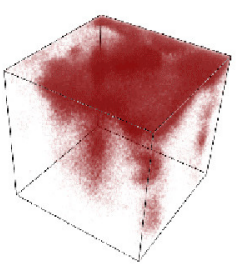

S-

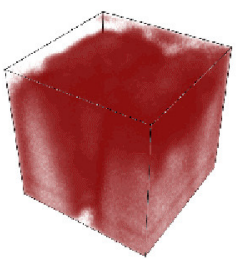

Cl-

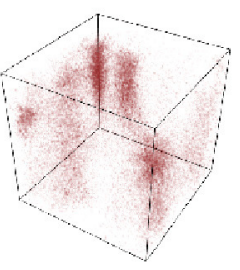

$\mathrm{SbO}_{2}^{-}$

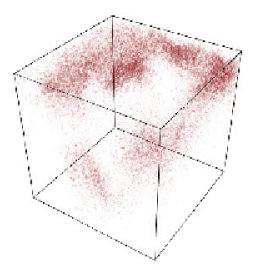

AuHg-

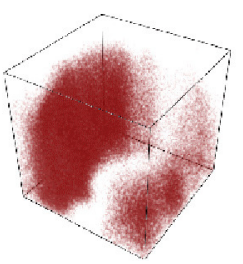

$\mathrm{CuCl}-$

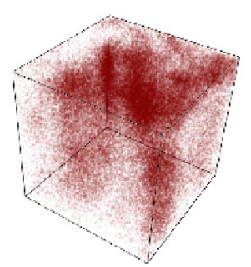

$\mathrm{SO}_{2}-$

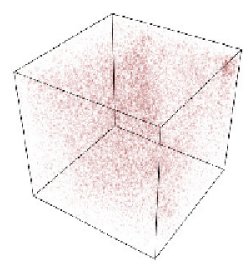

$\mathrm{HgCl}_{2}-$



$\mathrm{SiO}_{2}-$

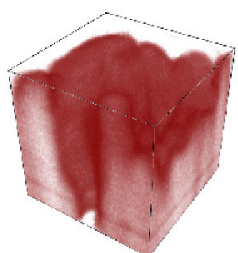

$\mathrm{Cu}-$

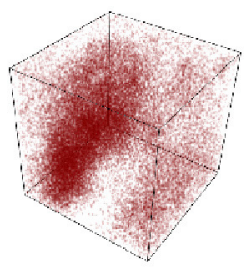

$\mathrm{CuCl}_{2}-$

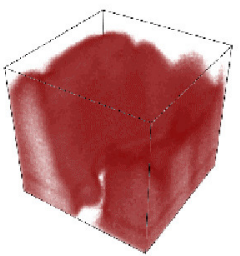

Cus-

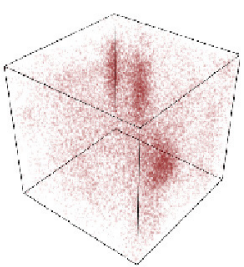

$\mathrm{PbCl}-$

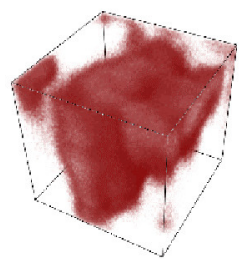

AlO-

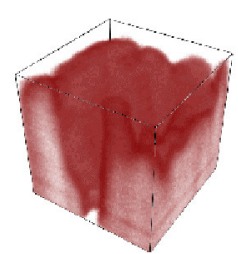

CuO-

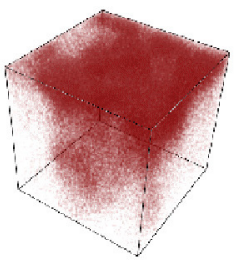

$\mathrm{Cu}_{3} \mathrm{H}_{2} \mathrm{O}_{2}-$

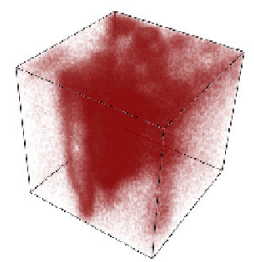

$\mathrm{PO}_{2}-$

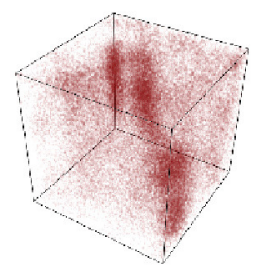

$\mathrm{PbO}-$

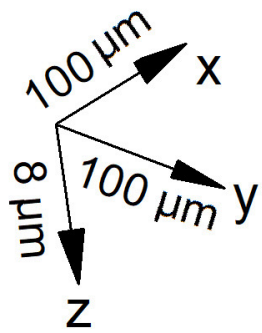

FIGURE 5 | ToF-SIMS 3D imaging of corroded area from gilded copper-based object showing the spatial distribution of selected ions. The reported ion signals were selected as representative of corrosion process and/or material coming from the burial soil. The sputtered away volume represented in the 3D renders was estimated to be $100 \times 100 \times 8 \mu \mathrm{m}^{3}$ by using profilometry.

and the sulfates on its top and in correspondence of the central channel. Considering the sample cleaning procedure, the typical high solubility of sulfates for the copper ion $\left(316 \mathrm{~g} / \mathrm{L}\right.$ at $\left.20^{\circ} \mathrm{C}\right)$ and finally the low amount found in the first layers, the signals of $\mathrm{SO}_{2}^{-}$are very likely related to a late recrystallization of an amount of sulfates which were originally formed among the corrosion layers during the burial. On the contrary, the high density of $\mathrm{CuS}^{-}$ion signals indicates the presence of its significant amount under the gold layer, as part of the internal corrosion layer together with copper oxides and chlorides thus revealing the 
presence of environmental sulfides species likely due to sulfate reducing bacteria (SRBs). Signals from $\mathrm{HgCl}_{2}^{-}$originate from diffuse points, especially in the middle of the analyzed volume. The distribution of $\mathrm{HgCl}_{2}^{-}$can be explained considering that mercuric chloride shows high solubility in water $\left(74 \mathrm{~g} / \mathrm{L}\right.$ at $\left.20^{\circ} \mathrm{C}\right)$ and could move from the original positions, filling, in particular, the cracks of the gold layer. $3 \mathrm{D}$ renders for $\mathrm{PbO}^{-}, \mathrm{PbCl}^{-}$, and $\mathrm{SbO}_{2}^{-}$ions show thickenings of points originating signals at common positions, whose longest dimensions range between $1 \div 4 \mu \mathrm{m}$. These values are comparable with those found in the FE-SEM BSE images for lead islands (such as in Figure 1B or in Ingo et al., 2018), thus confirming this interpretation of their nature. It is worth notice also that the few diffuse points from $\mathrm{PbO}^{-}$and $\mathrm{PbCl}^{-}$are mainly in correspondence of the central channel, as preferred accumulation site of the degradation products. $3 \mathrm{D}$ renders for $\mathrm{PO}_{2}^{-}, \mathrm{SiO}_{2}^{-}$, and $\mathrm{AlO}^{-}$ show the presence of a thickening elongated on the $\mathrm{z}$ direction, ideally in correspondence of the limit surface of the central channel. The presence of $\mathrm{PO}_{2}^{-}$ions is very likely to be related to organic or biological compounds which penetrated through the sample surface defects. Differently from chlorine, these ions did not diffuse in the substrate to react and form compounds. As seen in Figures 3C,D, the 3D spatial coherence of $\mathrm{SiO}_{2}^{-}$ and $\mathrm{AlO}^{-}$ion source points in the same conic sub-volume supports the hypothesis that clay (silico-aluminates) penetrated through an accessible crack in the gilding layer (the central channel) toward the inside of the object during its burial in the soil.

\section{CONCLUSIONS}

ToF-SIMS was employed to fully explore the external part of an ancient gilded copper buckle, which has been subjected to a long-term burial in the soil causing the degradation. ToF-SIMS enabled to obtain accurate, stratigraphic, spatially referred information about the elemental, ionic, and molecular composition of constituent materials and degradation products of the object. In particular, it emerged that:

- Surface defects in addition to micro and nanochannels present on the gold surface represent the access door for organic, inorganic, and biological material.

- The presence of chlorine, phosphorus and oxygen leads to the formation of several corrosion products, such as cuprite, nantokite, atacamite.

- 3D chemical maps clearly show the new altered composite layered structure formed during the long-term burial in the soil

\section{REFERENCES}

Abdelhamid, M., Angelini, E., Grassini, S., Ingo, G. M., and El Harith, M. (2010). Depth profiling of coated metallic artefacts adopting laser-induced breakdown spectrometry. Spectrochim. Acta B 65, 695-701. doi: 10.1016/j.sab.2010.03.017

Adriaens, A. (2005). Non-destructive analysis and testing of museum objects: an overview of 5 years of research. Spectrochim. Acta Part B 60, 1503-1516. doi: 10.1016/j.sab.2005.10.006 where the nantokite is located below the atacamite. In the same maps it is possible to observe the eruption of atacamite from the copper substrate.

- Chlorine and oxygen also interact with impurities and minor constituent materials leading to the formation of degradation products, such as $\mathrm{HgCl}_{2}, \mathrm{PbCl}_{2}, \mathrm{~Pb}$ oxides and $\mathrm{Sb}$ oxides.

- The interaction with the environment is proved by the presence of aluminosilicates within the surface defects but also by the presence of molecular species, such as $\mathrm{SO}_{2}^{-}$and $\mathrm{PO}_{2}^{-}$ that indicate a possible microbial induced corrosion (MIC). This latter aspect will be deeply investigated in future work.

Depth profiles and 3D renders were provided for all the species detected as graphical tools to investigate the internal structure of the sample, without sampling and cross-sectioning. Such information can be useful to generate models for the corrosion of this class of artifacts.

\section{DATA AVAILABILITY STATEMENT}

The datasets generated for this study are available on request to the corresponding author.

\section{AUTHOR CONTRIBUTIONS}

VG and MI drafted the work and conducted ToF-SIMS experiments and analysis. MA, CR, and GD carried sample treatment and sectioning, and conducted SEM-EDS analyses. GD and $\mathrm{PB}$ revised and commented on the manuscript. LT designed the research, conceptualized, and reviewed the paper.

\section{FUNDING}

LT would like to thank Fondazione Roma (Grant 5229441F37) for research funding. He also acknowledges funding from Regione Lazio under the Project MUSA n. B86C17000280002, and Project ADAMO n. B86C18001220002 of the Excellence Centre at the Lazio Technological District for Cultural Heritage (DTC).

\section{ACKNOWLEDGMENTS}

Low energy ion beam analysis experiments were performed at the Surface Analysis Laboratory Roma Tre, which is part of laboratories within the Italian Institute for Nuclear Physics (INFN) network CHNet and the Excellence Center of the Lazio Technological District for Cultural Heritage (DTC). 
bronze and copper artificial patinas. Appl. Surf. Sci. 255, 6378-6385. doi: 10.1016/j.apsusc.2009.02.020

Bastidas, D. M., Cano, E., González, A. G., Fajardo, S., Lleras-Pérez, R., Campo-Montero, E., et al. (2008). An XPS study of tarnishing of a gold mask from a pre-Columbian culture. Corros. Sci. 50, 1785-1788. doi: 10.1016/j.corsci.2008.04.009

Bastidas, D. M., Criado, M., Fajardo, S., La Iglesia, V. M., Cano, E., and Bastidas, J. M. (2010). Copper deterioration: causes, diagnosis and risk minimisation. International Materials. Reviews 55, 99-127. doi: 10.1179/095066009X12506721665257

Biocca, P., Santopadre, P., Sidoti, G., Sotgiu, G., de Notaristefani, F., and Tortora, L. (2016). ToF-SIMS study of gilding technique in the fresco Vela della Castità by Giotto's school. Surf. Interface Anal. 48, 404-408. doi: 10.1002/sia.5956

Bonaduce, I., Boon, J. J., Colombini, M. P., and Lanterna, G. (2007). "Chemical imaging techniques for the characterization of materials and techniques in the art of gilding: a case study from a mural painting by F. Lippi," in Proceedings of Conservation Science, eds J. H. Townsend, L. Toniolo, and F. Cappitelli (London: Archetype Books), 121-130.

Chiavari, C., Bernardi, E., Balbo, A., Monticelli, C., Raffo, S., Bignozzi, M. C., et al. (2015). Atmospheric corrosion of fire-gilded bronze: corrosion and corrosion protection during accelerated ageing tests. Corros. Sci. 100, 435-447. doi: 10.1016/j.corsci.2015.08.013

De Ryck, I., Adriaens, A., Pantos, E., and Adams, F. (2003). A comparison of microbeam techniques for the analysis of corroded ancient bronze objects. Analyst 128, 1104-1109. doi: 10.1039/b303588c

Di Tullio, V., Capitani, D., Atrei, A., Benetti, F., Perra, G., Presciutti, F., et al. (2016). Advanced NMR methodologies and micro-analytical techniques to investigate the stratigraphy and materials of 14 th century Sienese wooden paintings. Microchem. J. 125, 208-218. doi: 10.1016/j.microc.2015.11.036

Dowsett, M. G., Adriaens, A., Soares, M., Wouters, H., Palitsin, V. V. N., Gibbons, R., et al. (2005). The use of ultra-low-energy dynamic SIMS in the study of the tarnishing of silver. Nuclear Instrum. Methods Phys. Res. B 239, 51-64. doi: 10.1016/j.nimb.2005.06.179

Hackea, A. M., Carra, C. M., and Brown, A. (2004). "Characterisation of metal threads in Renaissance tapestries," in Proceedings of Metal 2004, eds J. Ashton and D. Hallam (Canberra, ACT: National Museum of Australia), 415-426.

Ingo, G. M., Angelini, E., Bultrini, G., De Caro, T., Pandolfi, L., and Mezzi, A. (2002). Contribution of surface analytical techniques for the microchemical study of archaeological artefacts. Surf. Interface Analysis 34, 328-336. doi: 10.1002/sia.1311

Ingo, G. M., Guida, G., Angelini, E., Di Carlo, G., Mezzi, A., and Padeletti, G. (2013). Ancient mercury-based plating methods: combined use of surface analytical techniques for the study of manufacturing process and degradation phenomena. Acc. Chem. Res. 46, 2365-2375. doi: 10.1021/ar300232e

Ingo, G. M., Riccucci, C., Guida, G., Albini, M., Giuliani, C., and Di Carlo, G. (2019). Rebuilding of the burial environment from the chemical biography of archeological copper-based artifacts. ACS Omega 4, 11103-11111. doi: 10.1021/acsomega.9b00569

Ingo, G. M., Riccucci, C., Lavorgna, M., Salzano de Luna, M., Pascucci, M., and Di Carlo, G. (2016). Surface investigation of naturally corroded gilded copper-based objects. Appl. Surf. Sci. 387, 244-251. doi: 10.1016/j.apsusc.2016. 06.082

Ingo, G. M., Riccucci, C., Pascucci, M., Messina, E., Giuliani, C., Biocca, P., et al. (2018). Combined use of FE-SEM+EDS, ToF-SIMS, XPS, XRD and OM for the study of ancient gilded artefacts. Appl. Surf. Sci. 446, 168-176. doi: 10.1016/j.apsusc.2018.01.278

Iorio, M., Graziani, V., Lins, S., Ridolfi, S., Branchini, P., Fabbri, A., et al. (2019). Exploring manufacturing process and degradation products of gilt and painted leather. Appl. Sci. 9:3016. doi: 10.3390/app9153016
Lechtman, H. (1984). Pre-Columbian surface metallurgy. Sci. Am. 250, 38-45. doi: 10.1038/scientificamerican0684-56

Lins, P. A., and Oddy, W. A. (1975). The origins of mercury gilding. J. Archaeol. Sci. 2, 365-373. doi: 10.1016/0305-4403(75)90007-2

Lucey, V. F. (1972). Developments leading to the present understanding of the mechanisms of pitting corrosion of copper. Br. Corros. J. 7, 36-41. doi: 10.1179/000705972798323332

Masi, G., Chiavari, C., Avila, J., Esvan, J., Raffo, S., Bignozzi, M. C., et al. (2016). Corrosion investigation of fire gilded bronze involving high surface resolution spectroscopic imaging. Appl. Surf. Sci. 366, 317-327. doi: 10.1016/j.apsusc.2016.01.101

Oddy, W. A. (1981). Gilding through the Ages. Gold Bull. 14, 75-79. doi: 10.1007/BF03214601

Oddy, W. A. (1990). Gilding: an outline of the technological history of the plating of gold on to silver or copper in the old world. Endeavour 15, 29-33. doi: 10.1016/0160-9327(91)90085-P

Podany, J., and Considine, B. B. (1994). Symposium organised by the Paul Getty Museum Proc. Malibou, USA: Paul Getty Museum.

Pope, D., Gibbens, H. R., and Moss, R. L. (1968). The tarnishing of silver at naturally occurring $\mathrm{H} 2 \mathrm{~S}$ and $\mathrm{SO} 2$ levels. Corros. Sci. 8, 883-887. doi: 10.1016/S0010-938X(68)80141-6

Robbiola, L., Blengino, J. M., and Fiaud, C. (1988). Morphology and mechanisms of formation of natural patinas on archaeological Cu-Sn alloys. Corros. Sci. 40, 2083-2111. doi: 10.1016/S0010-938X(98)00096-1

Sandu, I. C. A., de Sá, M. H., and Pereira, M. C. (2011). Ancient 'gilded' art objects from European cultural heritage: a review on different scales of characterization. Surf. Interface Anal. 43, 1134-1151. doi: 10.1002/sia.3740

Schreiner, M., and Grasserbauer, M. (1985). Microanalysis of art objects: objectives, methods and results. Fresenius J. Anal. Chem. 322:181. doi: 10.1007/BF00517657

Scott, D. A. (1985). Periodic corrosion phenomena in bronze antiquities. Stud. Conserv. 30, 49-57. doi: 10.1179/sic.1985.30.2.49

Scott, D. A. (1990). Bronze disease: a review of some chemical problems and the role of relative humidity. J. Am. Inst. Conserv. 29, 193-206. doi: $10.2307 / 3179583$

Scott, D. A. (1991). Metallography and Microstructure of Ancient and Historic Metals. Marina del Rey, LA: Getty Conservation Institute in association with Archetype Books.

Tortora, L., de Notaristefani, F., and Ioele, M. (2014). ToF-SIMS investigation of gilt and painted leather: identification of indigo, oil binder and gold varnish. Surf. Interface Anal. 46, 807-811. doi: 10.1002/sia.5450

Van Ham, R., Van Vaeck, L., Adams, F., and Adriaens, A. (2005). Feasibility of analyzing molecular pigments in paint layers using TOF S-SIMS. Anal. Bioanal. Chem. 383, 991-997. doi: 10.1007/s00216-005-0088-4

Yin, Y. S., Chen, B. J., and Ling, Y. C. (2008). ToF-SIMS study of official seals from Han Dynasty. Appl. Surf. Sci. 255, 1534-1537. doi: 10.1016/j.apsusc.2008.05.160

Conflict of Interest: The authors declare that the research was conducted in the absence of any commercial or financial relationships that could be construed as a potential conflict of interest.

Copyright (C) 2020 Graziani, Iorio, Albini, Riccucci, Di Carlo, Branchini and Tortora. This is an open-access article distributed under the terms of the Creative Commons Attribution License (CC BY). The use, distribution or reproduction in other forums is permitted, provided the original author(s) and the copyright owner(s) are credited and that the original publication in this journal is cited, in accordance with accepted academic practice. No use, distribution or reproduction is permitted which does not comply with these terms. 